\title{
Impact of Machine Magnetization State on Permanent Magnet Losses in Permanent Magnet Synchronous Machines
}

\author{
Daniel Fernández ${ }^{1}$, María Martinez, David Reigosa ${ }^{1}, J_{u a n}$ Guerrero$^{1}$, Carlos Suarez $^{2}$, Fernando Briz ${ }^{1}$ \\ ${ }^{1}$ Dept. of Elect., Computer \& System Engineering \\ ${ }^{2}$ Construction and Fabrication Engineering Department \\ University of Oviedo, Gijón, Spain \\ fernandezalodaniel@uniovi.es, martinezgmaria@uniovi.es, diazdavid@uniovi.es, guerrero@uniovi.es, csuarez@uniovi.es, \\ fernando@isa.uniovi.es
}

\begin{abstract}
Negative $d$-axis current injection used in interior permanent magnet synchronous machines (PMSMs) weakens the permanent magnets' (PM) flux, eventually increasing the PMs losses and reduces therefore the machine efficiency. Several studies have reported the increase in the airgap flux harmonic content as the primary reason for the PM losses increase in flux weakening operation, disregarding PM properties variation with the magnetization state (MS) due to PM magnetoresistive effect. This paper analyzes the variation of PM losses with the MS and flux weakening current, the target being threefold: a better understanding of PM losses production mechanisms; to analyze the impact of MS on the thermal behavior of the machine; use this knowledge to improve the machine design. ${ }^{1}$
\end{abstract}

Keywords-Permanent Magnet losses, Magnetization State, Magnetoresistance, flux weakening.

\section{INTRODUCTION}

PMSMs used in traction applications like electric or hybrid electric vehicles (EVs, HEV) require wide speed operation. High speed operation in conventional PMSMs, i.e. interior PMSMs (IPMSMs) and surface PMSMs (SPMSMs), requires injection of negative current in the $d$-axis [1]-[2] to produce flux weakening $d$-axis current is also used below rated speed in IPMSMs to achieve maximum torque per ampere (MTPA) [1]. In addition to weaken the stator flux linkage, $d$ axis current also increases the air-gap flux harmonic content, which increase Eddy current losses in the stator/rotor cores and PMs [1]-[3]. Stator core Eddy current losses are produced by both fundamental and harmonic components of the flux. On the contrary, the fundamental excitation does not induce Eddy current losses in the rotor core and PM, these are due to flux

\footnotetext{
${ }^{1}$ This work was supported in part by Spanish Ministry of Education, Culture and Sports through "José Castillejo Program" under grant PX15/00354, by Regional Ministry of Education, Culture and Sport of the Principality of Asturias through "Severo Ochoa Program" under Grant BP-13067 and by the Research, Technological Development and Innovation Programs of the Spanish Ministry Economy and Competitiveness, under grant MINECO-17ENE2016-80047-R
}

harmonics which do not rotate synchronously with the rotor, [4]-[7]. Such harmonics can be produced by non-idealsinusoidal distribution of airgap flux, due e.g. to nonsinusoidal currents, confinement of the stator windings into the stator slots, etc. Eddy current losses can significantly contribute to the overall temperature raise in PMSMs, increasing the risk of PM demagnetization [2]-[3],[8]. Hysteresis losses are typically less relevant since the magnetic materials in PMSMs always operate in the second quadrant of B-H curve [8].

Variable flux PMSMS (VF-PMSMs) are becoming a promising choice for EVs and HEVs. These applications require high staring torque and high efficiency throughout a wide speed range. VF-PMSMs avoid the drawbacks of field weakening current by permanently demagnetizing/ magnetizing the PMs of the machine according to its working condition. This is done during normal operation by means of a current pulse which is injected in the stator [9]-[11]

Changes in the flux of either traditional PMSMs and VFPMSMs will affect in most cases to core saturation, and consequently of its resistivity due to the magnetoresisitive effect [14]. Such effect was reported in [15] for $\mathrm{NdFeB}$ magnets. It was shown in [13] that both PM magnetization state and flux-weakening current influence the air-gap magnetic field harmonic content and the PM and core resistivity. This was the base for the magnetization state estimation method proposed in [12]. While both magnetization state and flux-weakening current can potentially affect to rotor and stator losses, only the first one has been studied and reported in the literature [16]-[18]. To the best of authors knowledge, effects of variation of the PM and core resistivity on machine's efficiency has not been studied yet.

This paper analyzes the relationship between PM losses, PM MS and flux-weakening $d$-axis current injection in PMSMs [19]. Preliminary analysis is carried out using PM samples, as this allows a more precise study of the phenomena occurring in the PMs. The analysis is then extended to 
PMSMs. While the paper will focus on conventional PMSM, analysis and conclusions can be extended to VF-PMSM.

The paper is organized as follows: magnetoresistive effect in PMs and the variation of induced Joule losses due to this effect are discussed in section II. PM Joule losses estimation using a simplified geometry and the impact of circuit parameters on PM losses due to Eddy currents is analyzed in section III. Experimental results using magnet samples are provided in this section. Experimental results for the case of an IPMSMs are presented in section IV. Finally, conclusions are provided in section $\mathrm{V}$.

\section{MAGNETORESISTANCE AND EdDY CURRENTS}

Magnetoresistance $(M R)$ is the change of a material electrical resistivity with the magnetic field (1) [14]. In general the magnetic field results from the combined effect of the material internal magnetic field (e.g. permanent magnet materials) and of the external magnetic field being applied.

$$
\begin{gathered}
M R=\frac{\Delta \rho}{\rho_{\mathrm{H}_{0}}}=\frac{\rho_{\mathrm{H}}-\rho_{\mathrm{H}_{0}}}{\rho_{\mathrm{H}_{0}}} \\
\rho_{H}=\rho_{H_{0}}\left(1+\beta\left(\mathrm{H}-\mathrm{H}_{0}\right)\right)
\end{gathered}
$$

where $\rho_{H_{0}}(2)$ is the resistivity of the material in the absence of a magnetic field (i.e. $H_{0}=0$ ) for a demagnetized magnet, $\rho_{H}$ is the actual resistivity of the material when a given external field $H$ is applied. Material resistivity is a function of $\beta$, which is the coefficient that links the PM flux and the material resistivity variation. Magnetoresistive effect is especially important in $\mathrm{NdFeB}$ permanent magnets [12], which is the primary option in commercial PMSMs [20] (IPMSMs and SPMSMs). When MS of a NdFeB PM is changed or its flux is weakened by an external field (e.g. due to flux-weakening current), its electrical resistivity varies.

Changes of the electrical resistivity of a conductive material subjected to a time varying field will have a direct impact on the Joule losses due to the induced Eddy currents. Power losses due to Eddy currents in the magnet can be expressed as (3) assuming that the skin effect can be neglected; where $B_{m n}$ and $f_{n}$ are the amplitude and frequency of the $\mathrm{n}^{\text {th }}$ harmonic of the magnetic field respectively; $\rho$ is the resistivity of the magnet and $K_{e}$ is a constant that accounts for diffusion effects and depends on material surface uniformity, PM shape, composition and density [5], [7], [21].

$$
P_{\text {eddy }}=\sum_{n} K_{e} \frac{\left(B_{m n} f_{n}\right)^{2}}{\rho(H)}=\sum_{n} R_{n} I_{n}^{2}
$$

It is observed from (3) that the losses are proportional to the square of the magnetic field amplitude $\left(B_{m n}\right)$ and frequency $\left(f_{n}\right)$ and inversely proportional to the resistivity of the material $(\rho)$, which changes with the magnetic field due to MR effect (1)-(2). Joule losses can also be expressed as a function of the induced $\mathrm{n}^{\text {th }}$ current harmonic $I_{n}$ and magnet resistance at that frequency $R_{n}$.

\section{PM EDDY-CURRENT Loss ESTIMATION USING A SYMPLIFYED GEOMETRY}

Estimation of the PM losses due to Eddy currents in PMSMs can be extremely difficult once it is assembled, due to the large number of design parameters that can affect [2]. Use of PM samples for this purpose offers some relevant advantages in this regard. A setup has been developed to analyze magnetoresistance and Eddy current loss in PM samples. Detailed description of the experimental setup in included in appendix I.

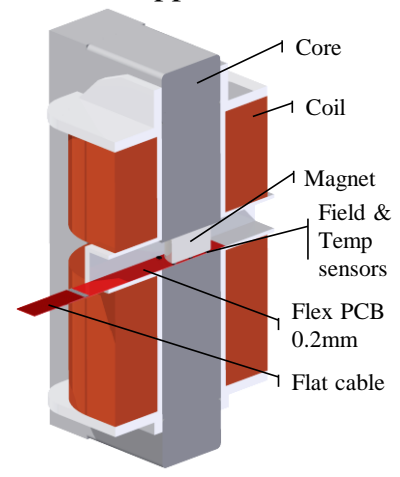

a)

b)

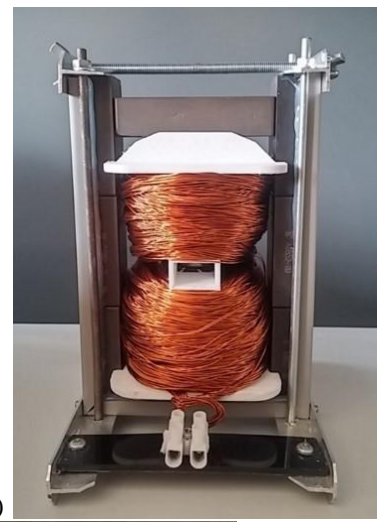

c)

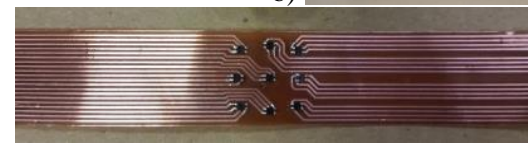

PM for the experimental setup

PM for an IPMSM

d)

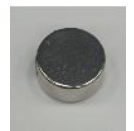

Fig. 1. a) Cross-Section of experimental setup used for PM magnetoresitance evaluation, b) picture of the experimental setup, c) flexible PCB including field and temperature sensors and d) magnet samples to be used in the experimental setup $(\varnothing 20 \times 10 \mathrm{~mm})$ and in the IPMSM $(42 \times 50 \times 6 \mathrm{~mm})$.

\section{A. Equivalent HF circuit}

The equivalent HF circuit of the experimental setup shown in Fig. 1a is shown in Fig. 2, where primary and secondary sides represent the coil and PM respectively. The HF model is described by (4) for the primary side and (5) for the secondary side, where $R_{h f p}^{p}$ and $R_{h f s}^{s}$ are the coil and magnet HF resistances, $L_{h f p}^{p}$ and $L_{h f s}^{s}$ are the coil and magnet HF inductances, $\omega_{h f}$ is the frequency of the injected HF signal, $v_{h f p}^{p}$ is the coil HF voltage, $i_{h f p}^{p}$ is the coil HF current, $i_{h f s}^{s}$ magnet HF current (Eeddy current). The turns ratio is determined implicitly by the mutual coupling between the primary and secondary, $M_{p s}(6)$ which depends on the mutual coupling coefficient, $k$, and system inductances. The secondary high frequency current, $i_{h f s}^{s}$, can be obtained directly from (5) as a function of the primary current, $i_{h f p}^{p}$, mutual coupling, $M_{p s}$, magnet HF impedance.

$$
\begin{aligned}
& v_{h f p}^{p}=\left(R_{h f p}^{p}+j \omega_{h f} L_{h f p}^{p}\right) i_{h f p}^{p}+j \omega_{h f} M_{p s} i_{h f s}^{s} \\
& 0=\left(R_{h f s}^{s}+j \omega_{h f} L_{h f s}^{s}\right) i_{h f s}^{s}+j \omega_{h f} M_{p s} i_{h f p}^{p} \\
& M_{p s}=k \sqrt{L_{h f s}^{s} L_{h f p}^{p}}
\end{aligned}
$$




$$
i_{h f s}^{s}=\frac{-j \omega_{h f} M_{p s} i_{h f p}^{p}}{\left(R_{h f s}^{s}+j \omega_{h f} L_{h f s}^{s}\right)}
$$

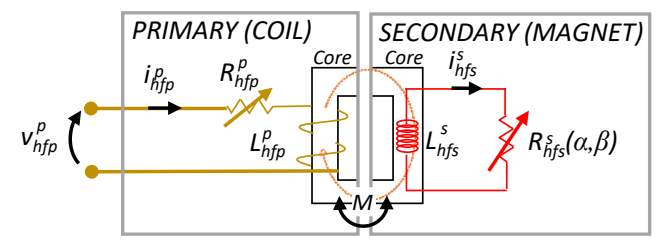

Fig. 2. Equivalent HF model of the simplified geometry.

\section{B. Sensitivity of $P_{\text {eddy }}$ to $H F$ circuit parameters}

This subsection analyzes the sensitivity of the Eddy current loss (see (3)) to: 1) magnet HF resistance $\left(R_{h f s}^{s}\right), 2$ ) frequency of the injected signal $\left.\left(\omega_{h f}\right), 3\right) \mathrm{HF}$ inductance of the magnet $\left.\left(L_{h f p}^{p}\right), 4\right) \mathrm{HF}$ inductance of the coil $\left(L_{h f s}^{s}\right)$ and 5) mutual coupling coefficient $(k)$. The analysis considers only one harmonic component; extrapolation of the results for multiple harmonic components is straightforward from (3). Provided that $R_{n}=R_{h f s}^{s}$ in the HF equivalent circuit, see (4)(7), and that $I_{n}=I_{h f s}^{s},(8)$ is obtained form (4), where $I_{h f s}^{s}$ and $I_{h f p}^{p}$ are the magnitudes of $i_{h f s}^{s}$ and $i_{h f p}^{p}$ respectively.

$$
P_{e d d y}=R_{n} I_{n}^{2}=R_{h f s}^{s} \frac{\left(\omega_{h f} k \sqrt{L_{h f s}^{s} L_{h f p}^{p}} I_{h f p}^{p}\right)^{2}}{\left(\left(R_{h f s}^{s}\right)^{2}+\left(\omega_{h f} L_{h f s}^{s}\right)^{2}\right)}
$$

Fig. 3 to Fig. 5 show the magnet high frequency current magnitude, $I_{h f s}^{s}$ and the magnet losses due to Eddy currents (8) vs. $R_{h f s}^{s}$ as a for different values of the mutual coupling
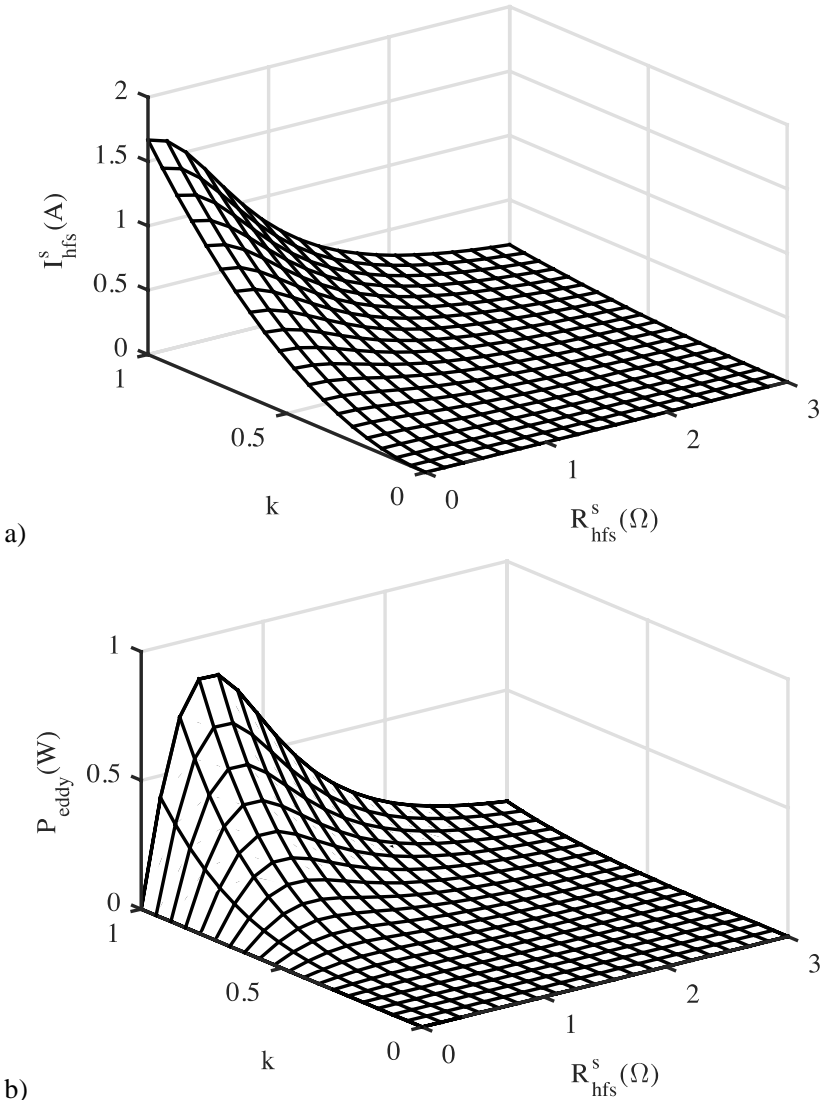

Fig. 3. a) Magnet high frequency current $I_{h f s}^{s}$, and b) magnet Eddy current losses $P_{e d d y}$, as a function of $R_{h f s}^{s}$ and $k$. $I_{h f s}^{s}=1 A, L_{h f s}^{s}=0.7 \mathrm{mH}$, $L_{h f p}^{p}=1 m H, R_{h f p}^{p}=1 \Omega$ and $\omega_{h f}=2 * \mathrm{pi} * 250 \mathrm{rad} / \mathrm{s}$. coefficient $k, L_{h f p}^{p}$ and the frequency of the injected signal, $\omega_{h f}$, respectively. In all cases $R_{h f s}^{s}$ varies from 0 to $3 \Omega$; Analysis presented in [4] and [12] showed that NdFeB PMs
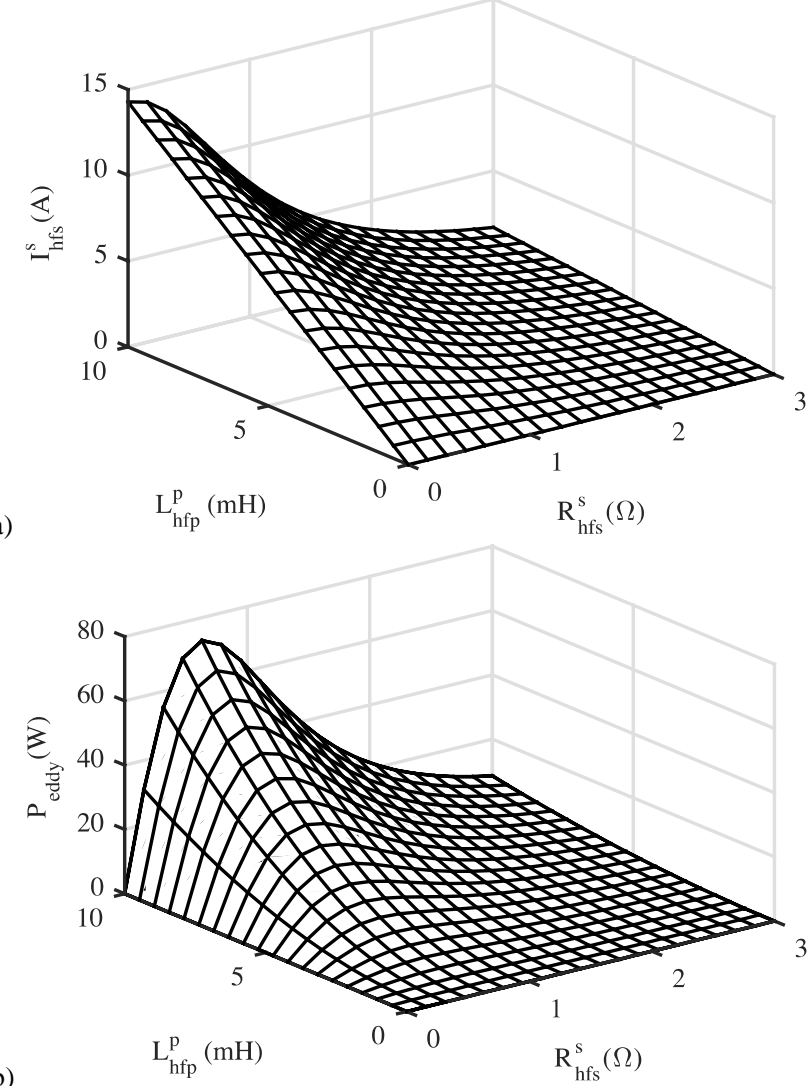

Fig. 4. a) Magnet high frequency current $I_{h f s}^{s}$, and b) magnet Eddy current losses $P_{e d d y}$, as a function of $R_{h f s}^{s}$ and $L_{h p p}^{p}$. $I_{h f s}^{s}=1 A$, $L_{h f s}^{s}=0.7 \mathrm{mH}, R_{h f p}^{p}=1 \Omega, k=0.75$ and $\omega_{h f}=2 * \mathrm{pi} * 250 \mathrm{rad} / \mathrm{s}$.
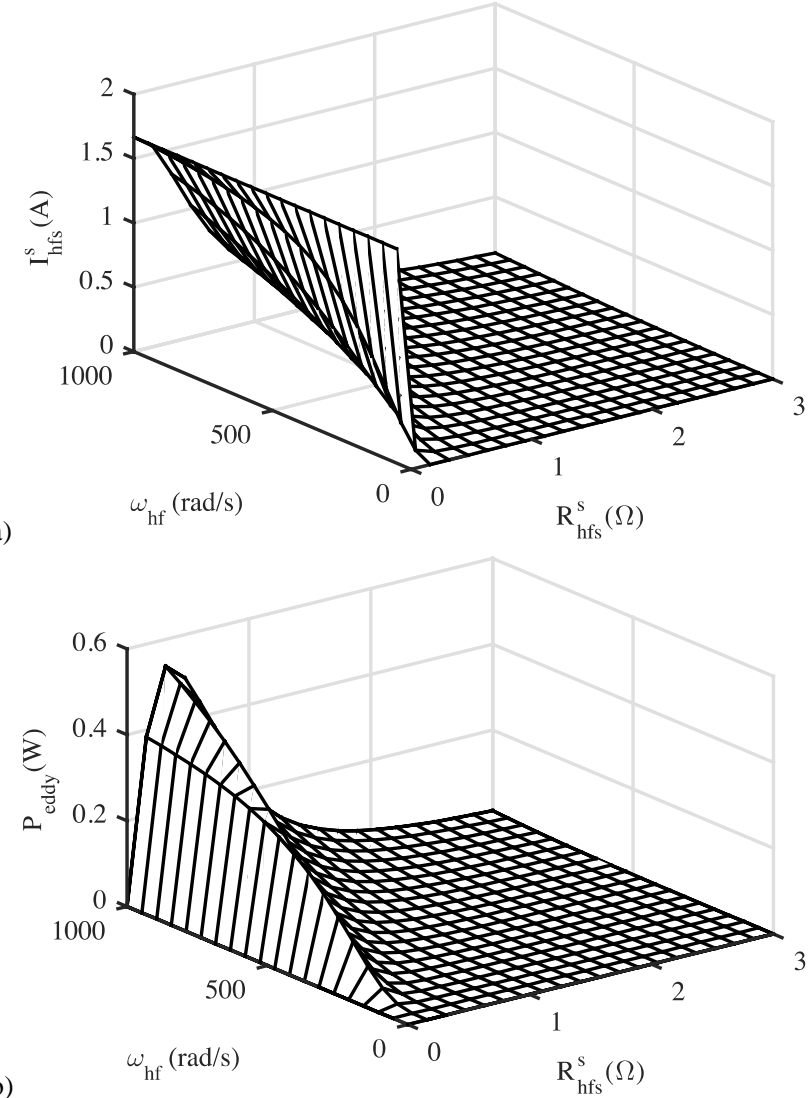


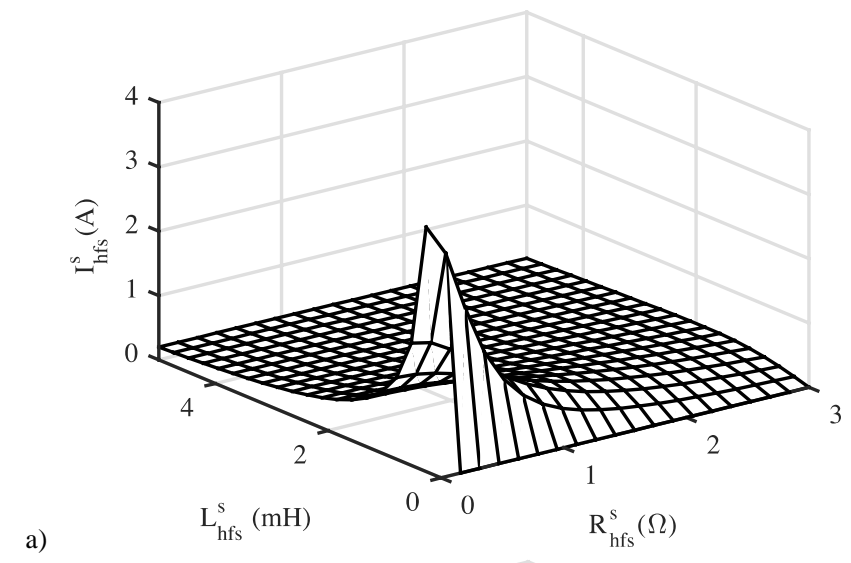

resemble the flux-weakening current once the PM is inserted in the rotor of PMSMs; for the second type, magnet samples with different MS are tested, no DC current is applied in this case. In both cases, a high frequency is injected, which is intended to resemble flux harmonics in PMSMs. The high frequency current is controlled to produce a high frequency flux on the PM surface of 70mT peak value. An example of the measured flux and corresponding frequency spectrum are shown in Fig. 7.

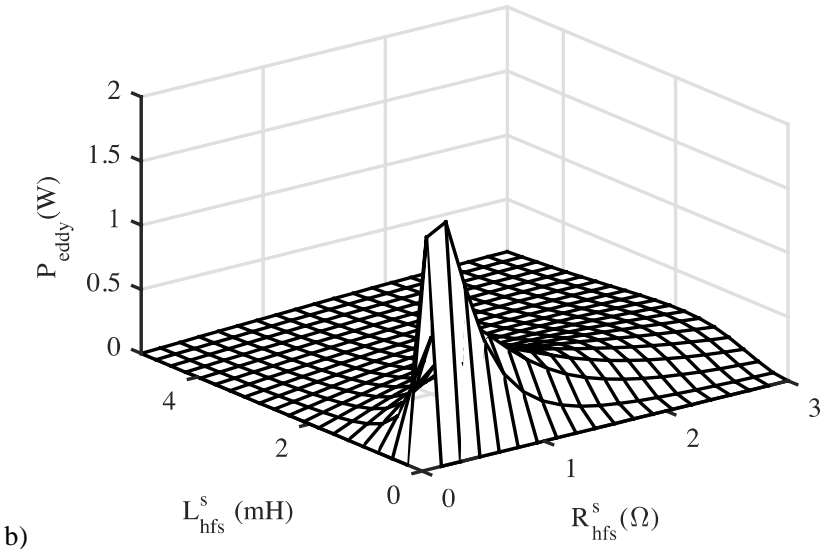

Fig. 6. a) Magnet high frequency current $I_{h f s}^{s}$, and b) magnet Eddy current losses $P_{e d d y}$, as a function of $R_{h f s}^{s}$ and $L_{h f s}^{s}$. $I_{h f s}^{s}=1 A, L_{h f p}^{p}=1 m H$, $R_{h p p}^{p}=1 \Omega, k=0.75$ and $\omega_{h f}=2 * \mathrm{pi} * 250 \mathrm{rad} / \mathrm{s}$.

Fig. 5. a) Magnet high frequency current $I_{h f s}^{s}$, and b) magnet Eddy current losses $P_{e d d y}$, as a function of $R_{h f s}^{s}$ and $\omega_{h f}$. $I_{h f s}^{s}=1 A$, $L_{h f s}^{s}=0.7 \mathrm{mH}, L_{h p p}^{p}=1 \mathrm{mH}, R_{h p p}^{p}=1 \Omega$ and $k=0.75$.

high frequency resistance $R_{h f s}^{s}$ is in a range of a few Ohms. It is observed that in all the three cases, $I_{h f s}^{s}$ decreases as $R_{h f s}^{s}$ increases. It is also observed that variation of $P_{e d d y}$ with $R_{h f s}^{s}$ is not monotonic, i.e. an increase of $R_{h f s}^{s}$ does not necessarily produces an increase of $P_{e d d y}$.

For all the three cases it can be observed that the lower $k$, $L_{h f p}^{p}$, or $\omega_{h f}$ are, the lower $I_{h f s}^{s}$ is; which results in lower $P_{e d d y}$.

Fig. 6 shows the magnet high frequency current magnitude and losses due to Eddy currents vs. $R_{h f s}^{s}$ and $L_{h f s}^{s}$ . It can be observed that contrary to $k, \omega_{h f}$ and $L_{h f p}^{p}$ cases shown in Figs. 3-5, an increase of $L_{h f s}^{s}$ does not result in an increase of $I_{h f s}^{s}$. This is explained by the fact that $L_{h f s}^{s}$ is present in both numerator and denominator of (8). $I_{h f s}^{s}$ is seen to always decrease with $R_{h f s}^{s}$. On the contrary, Eddy current losses, $P_{\text {eddy }}$ do not change monotonically neither with $R_{h f s}^{s}$ or $L_{h f s}^{s}$.

Based on the previous results and on the analysis shown in Figs. 3-6, it is expected that a decrease of $R_{h f s}^{s}$, e.g. due to flux weakening current (see section II.A), will result in an increase of both $I_{h f s}^{s}$ and $P_{e d d y}$. This issue will be confirmed experimentally in Sections II.D and IV.

\section{Experimental results}

Two different types of experiments have been conducted using magnet samples: for the first type, the PM is fully magnetized (i.e. 100\% MS) and a DC current, which weakens the PM field, is applied. The DC current is intended to
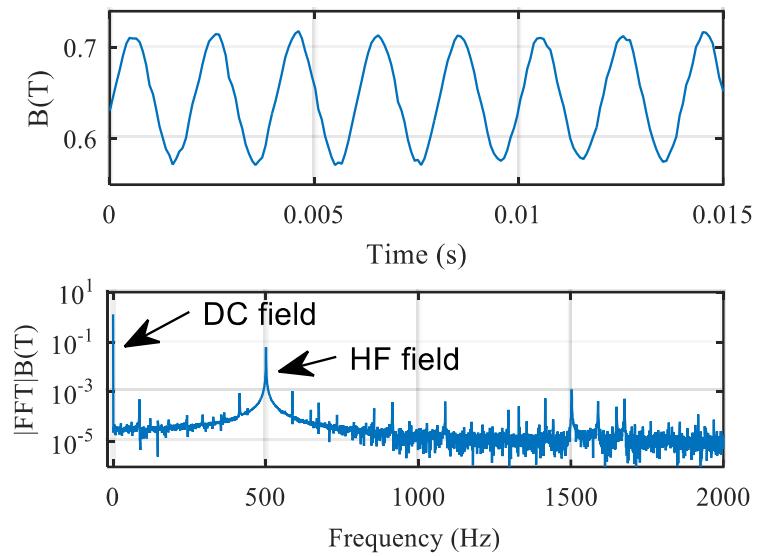

Fig. 7. Experimental results. a) Flux on the PM surface, and b) corresponding frequency spectrum, b). $\mathrm{I}_{\mathrm{DC}}=-10 \mathrm{~A}, \mathrm{f}_{\mathrm{hf}}=500 \mathrm{~Hz}$, high frequency current $i_{h f p}^{p^{*}}$ is controlled to produce a $500 \mathrm{~Hz}, 0.7 \mathrm{~T}$ peak high frequency flux.

Fig. 8a shows the measured PM temperature for the first type of experiments. The flux in the PM surface is in this case the result of the combined effect of the PM remanent flux (100\% MS in all experiments), and the flux resulting from the DC flux weakening current and high frequency current. DC flux weakening current is controlled to reduce the flux in the PM surface. Losses are induced by the high frequency flux exclusively. According to (2), PM resistivity will decrease as the flux weakening current increases, the induced power losses due to Eddy currents (3). Consequently, larger temperature increases are expected as temperature is a reliable indicator of PM losses [25]. This is confirmed by Fig. 8a. Table I shows the PM properties according to the PM manufacturer. The specific heat capacity of the PM is $440 \mathrm{~J}$ $\mathrm{kg}^{-1} \mathrm{~K}^{-1}$ and the magnet density is $7.55 \mathrm{~g} / \mathrm{cm}^{3}$. Mass of magnet in Fig. 1d. is $23.71 \mathrm{~g}$, energy required to raise its temperature $1^{\circ} \mathrm{C}$ being 10.43 Joules. Table II shows an estimation of the PM loss increment for the first 30 seconds in Figs. 8a and b.

a)

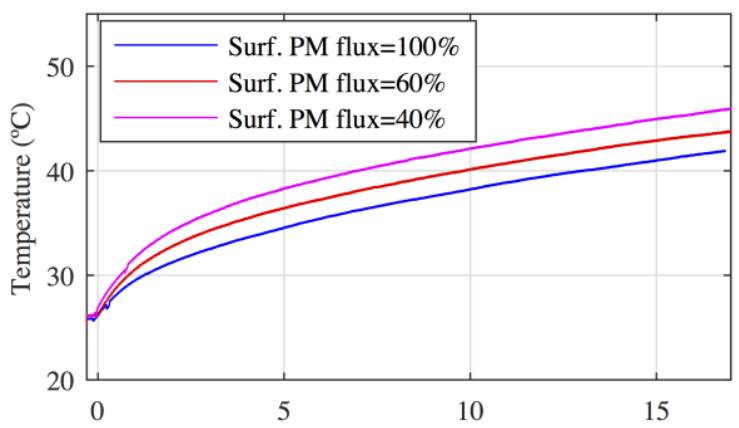




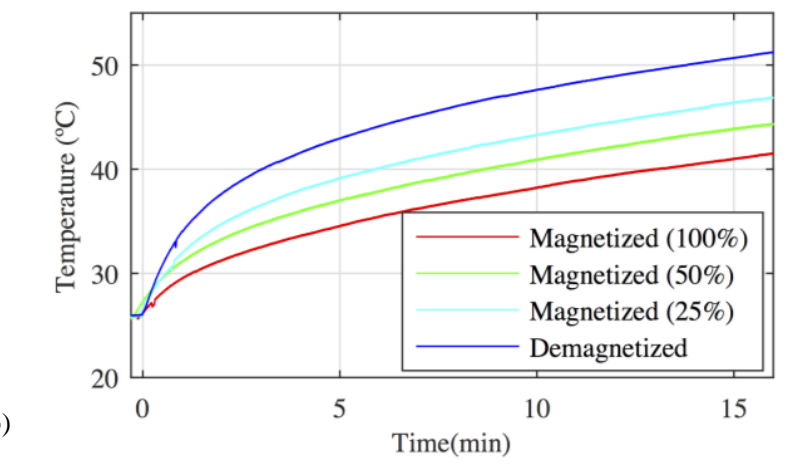

Fig. 8. Experimentally measured PM temperature vs. time: a) PM fully magnetized and DC field weakening current controlled to reduce the flux at the PM surface to $60 \%$ and $40 \%$ respectively); b) different PM remanent flux levels. A high frequency flux of $500 \mathrm{~Hz}, 0.7 \mathrm{~T}$ peak is applied.

Fig. $8 \mathrm{~b}$ shows the results for the second type of experiments. MS is varied from 0 to $100 \%$ in steps of $25 \%$ while room temperature is kept constant at $20^{\circ} \mathrm{C}$. Larger PM temperature increases are observed as MS decreases, which is consistent with (2)-(3).

TABLE I: PM MATERIAL PROPERTIES

\begin{tabular}{|l|c|c|c|}
\hline Material Property & Symbol & Value & Units \\
\hline Max. Operating Temperatura & $\mathrm{T}_{\max }$ & 120 & ${ }^{\circ} \mathrm{C}$ \\
\hline Density & $\mathrm{D}$ & 7.55 & $\mathrm{~g} / \mathrm{cm}^{3}$ \\
\hline Specific Heat Capacity & $\mathrm{c}$ & 440 & $\mathrm{~J} /(\mathrm{Kg} \mathrm{K})$ \\
\hline
\end{tabular}

TABLE II: ESTIMATION OF PM LOSS VARIATION

\begin{tabular}{|c|c|c|c|}
\hline & Value & $\Delta \mathrm{T}(30 \mathrm{~s})$ & $\Delta \mathrm{P}_{\text {loss }}$ \\
\hline Flux & $100 \%$ & $2.4^{\circ} \mathrm{C}$ & $0.83 \mathrm{~W}$ \\
\cline { 2 - 4 } weakening & $60 \%$ & $2.7^{\circ} \mathrm{C}$ & $0.93 \mathrm{~W}$ \\
\cline { 2 - 4 } Fig. 8a & $40 \%$ & $3.2^{\circ} \mathrm{C}$ & $1.11 \mathrm{~W}$ \\
\hline & $100 \% \mathrm{c}$ & $2.2^{\circ} \mathrm{C}$ & $0.76 \mathrm{~W}$ \\
\cline { 2 - 4 } Magnetization & $50 \%$ & $2.8^{\circ} \mathrm{C}$ & $0.97 \mathrm{~W}$ \\
\cline { 2 - 4 } state Fig. 8b & $25 \%$ & $3.4^{\circ} \mathrm{C}$ & $1.18 \mathrm{~W}$ \\
\cline { 2 - 4 } & $0 \%$ & $4.8^{\circ} \mathrm{C}$ & $1.67 \mathrm{~W}$ \\
\hline
\end{tabular}

It is concluded that losses due to Eddy currents in $\mathrm{NdFeB}$ magnets, and consequently temperature, increase as the overall field due to the combined effect of the PM remanent flux and the flux induced by the flux weakening current decrease. It is observed from the experimental results that PM temperature does not change linearly either with the fluxweakening current or the MS. Improvement of the analytical models is a subject of ongoing research.

TABLE III. IPMSM PARAMETERS
\begin{tabular}{|l|l|l|l|l|l|l|}
\hline PATED & $V_{\text {RATED }}$ & I $_{\text {RATED }}$ & $\omega_{\mathrm{r}}$ & Poles & Slots & Magnet \\
\hline $7.5 \mathrm{~kW}$ & $350 \mathrm{~V}$ & $14 \mathrm{~A}$ & $1800 \mathrm{rpm}$ & 6 & 36 & N-42SH \\
\hline
\end{tabular}

\section{EXPERIMENTAL RESULTS IN AN IPMSM}

Extension of the experimental verification to the case of an IPMSM is presented in this section. Machine parameters and design are shown in Table III and Fig. 9 respectively. Fig. 10 shows a picture of the machine. MS of the magnets is modified using the peak magnetizer shown in Fig 12. End shield of the machine has been modified to allow insertion/extraction of the magnets with no need to remove the rotor. This helps fast evaluation of multiple magnet configurations. The machine is also equipped with K-type thermocouples temperature sensors attached to the rotor at the location of PM1, PM 2 and PM 3 (see Fig. 9) using a thermally conductive epoxy adhesive. Thermocouple wires are taken out throughout a hole in the shaft and connected to a conditioning stage as shown in Fig. 12. The signal is filtered using an analog second order stage and further sampled and transmitted via $\mathrm{Wi}-\mathrm{Fi}$ at $1 \mathrm{~Hz}$. A schematic representation of the complete temperature measurement system is shown in Fig. 12.

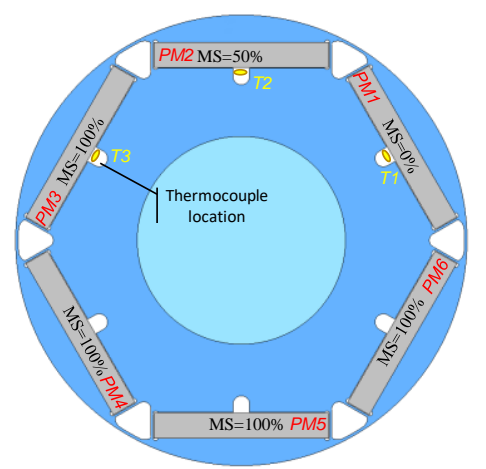

Fig. 9. Rotor design and schematic representation of the PM temperature measurement system. MS shown in the figure corresponds to case \#6 in Table IV.

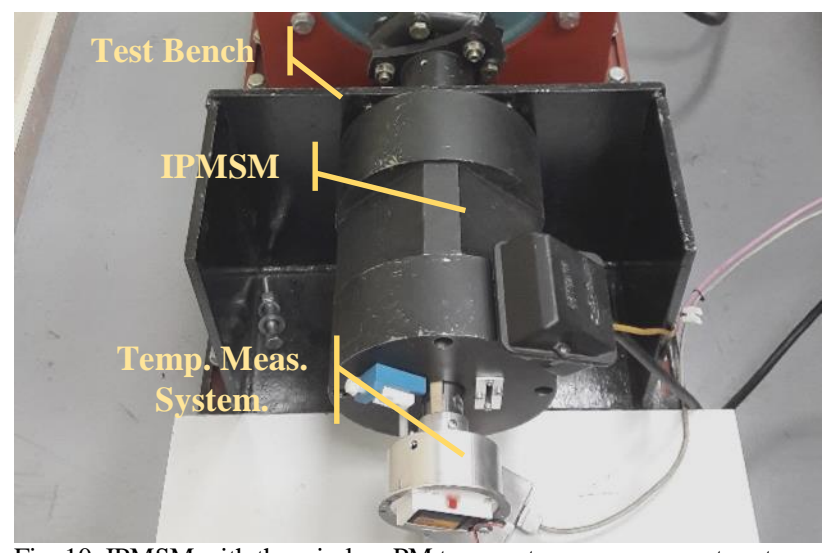

Fig. 10. IPMSM with the wireless PM temperature measurement system.

MS of the PMs is varied from $10 \%$ to $100 \%$, matching therefore the conditions of the experimental results shown in section III. Further details of the equivalence between both circuits can be found in [12] and [13]. Seven cases will be studied; they are shown in Table IV. In all cases the machine is loaded and rotates at $1000 \mathrm{rpm}$. A pulsating current of magnitude $0.25 \mathrm{pu}$ and frequency $250 \mathrm{~Hz}$ respectively is injected in the $d$-axis to induce additional losses in the PMs. Table IV shows the PMs MS configuration for the six pole IPMSM in Fig. 10. When the machine is partially demagnetized, the average PM flux linkage is weakened and therefore, the average torque developed by the machine for a given current will be also reduced. In addition since magnetization is not uniform (Cases \#2 to \#7) torque ripple will increase with respect to the uniform magnetization case [26], [27]. 
TABLE IV. EXPERIMENTS FOR DIFERNT MS

\begin{tabular}{|c|c|c|c|c|c|c|}
\hline & \multicolumn{7}{|c|}{ PM } \\
\hline CASE & $1(\mathrm{~T} 1)$ & $2(\mathrm{~T} 2)$ & $3(\mathrm{~T} 3)$ & 4 & 5 & 6 \\
\hline$\# 1$ & 100 & 100 & 100 & 100 & 100 & 100 \\
\hline$\# 2$ & 95 & 100 & 100 & 100 & 100 & 100 \\
\hline$\# 3$ & 90 & 100 & 100 & 100 & 100 & 100 \\
\hline$\# 4$ & 85 & 100 & 100 & 100 & 100 & 100 \\
\hline$\# 5$ & 80 & 100 & 100 & 100 & 100 & 100 \\
\hline$\# 6$ & 10 & 50 & 100 & 100 & 100 & 100 \\
\hline$\# 7$ & 60 & 95 & 100 & 100 & 100 & 100 \\
\hline
\end{tabular}

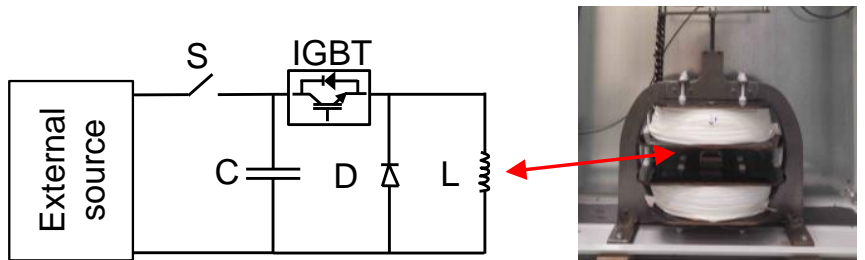

Fig. 11. Schematic representation of the circuit used for PM magnetization and demagnetization.

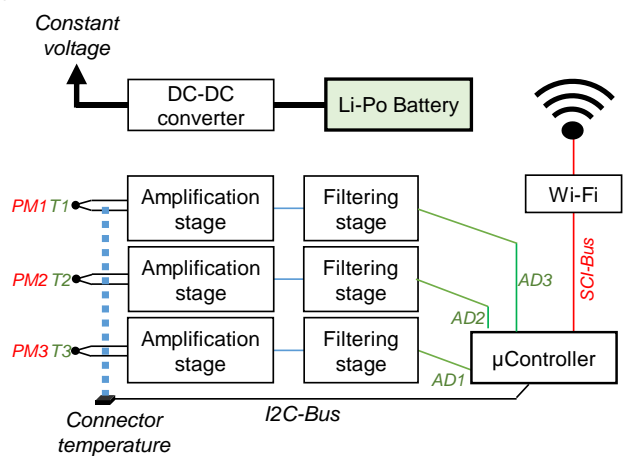

Fig. 12. Schematic representation of the PM temperature measurement system

Fig. 13 shows the PM temperature measured by thermocouples T1-T3 due to the injection of the HF current when all PMs fully magnetized (case \#1 in Table IV). Unbalances in PMs temperature are negligible. As the MS state of all PMs is the same, unbalances in the core losses and consequently in the temperature could only be due to anisotropy, which can be noticeable in grain-oriented electrical steel sheets [22]. However, steel sheets for the test machine have been randomly assembled; consequently, overall anisotropy of the stack is expected to be small.

Fig 14 shows experimental results when PM1 and PM2 MS is $65 \%$ and $95 \%$, i.e. case \#7 in the Table IV. It is observed that the temperature increases as the PM MS decreases, which is consistent with the theoretical predictions and with the results shown in Fig. 8b. Fig. 15 shows experimental results when PM1 and PM2 MS is $10 \%$ and $50 \%$ (case \#6 in the Table IV), i.e. high demagnetization degrees. The results are consistent with the results shown in Fig. $8 \mathrm{~b}$ and Fig. 14. The test was limited to $50 \mathrm{~min}$. to avoid overheating of the PMs, which could cause an irreversible damage.
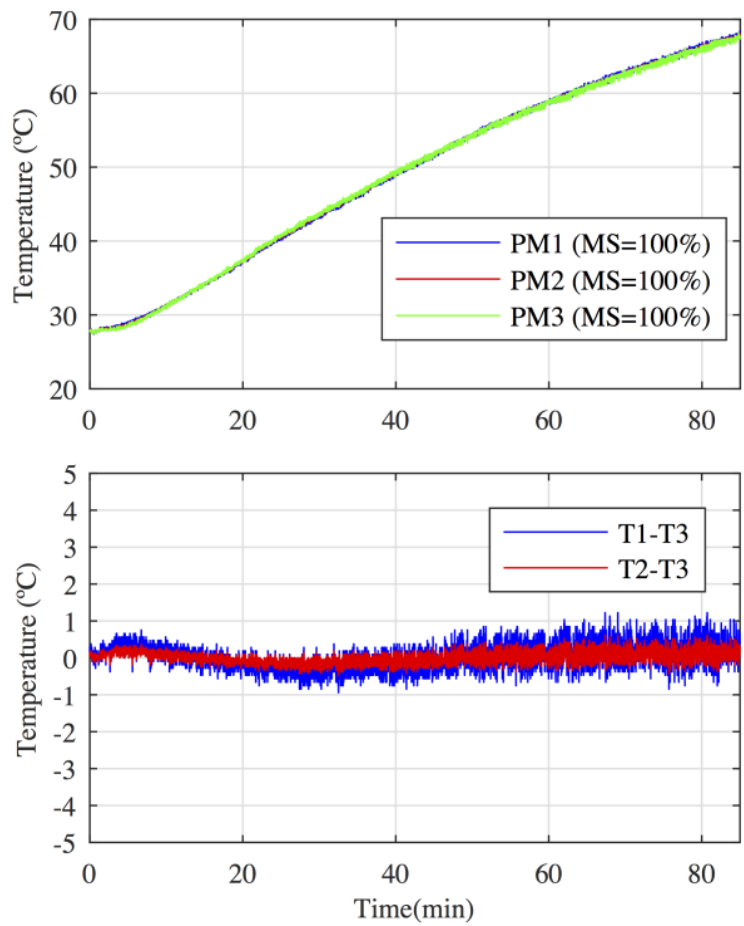

Fig. 13. a) Temperature of PMs 1 to 3 for case \#1 in Table IV; b) temperature difference among magnets. $\mathrm{I}_{\mathrm{q}}=0.5 \mathrm{pu}, \mathrm{I}_{\mathrm{d}}=0.5 \mathrm{pu}, \mathrm{Ih}_{\mathrm{f}}=0.25$ $\mathrm{pu}, \mathrm{fh}_{\mathrm{h}}=250 \mathrm{~Hz}$ and $\mathrm{wr}=1000 \mathrm{rpm}$.
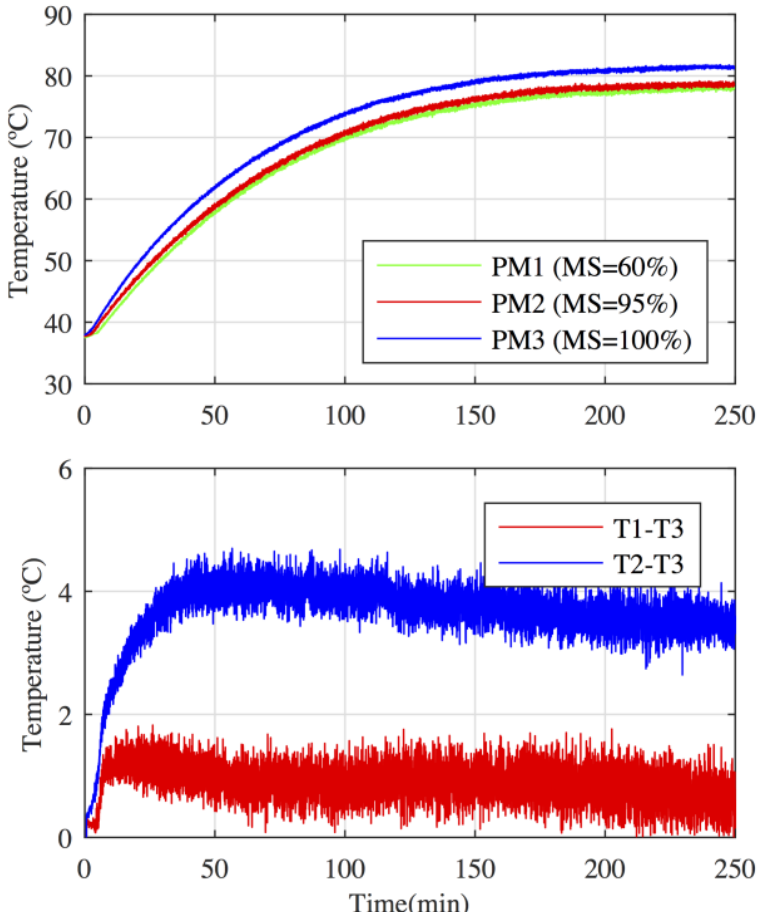

Fig. 14. a) Temperature of PMs 1 to 3 for case \#7 in Table IV; b) temperature difference among demagnetized PMs and fully magnetized magnets. $\mathrm{I}_{\mathrm{q}}=0.4 \mathrm{pu}, \mathrm{I}_{\mathrm{d}}=0.5 \mathrm{pu}, \mathrm{Ihf}_{\mathrm{f}}=0.25 \mathrm{pu}, \mathrm{fhf}_{\mathrm{h}}=250 \mathrm{~Hz}$ and $\mathrm{wr}_{\mathrm{r}}=1000$ rpm. 

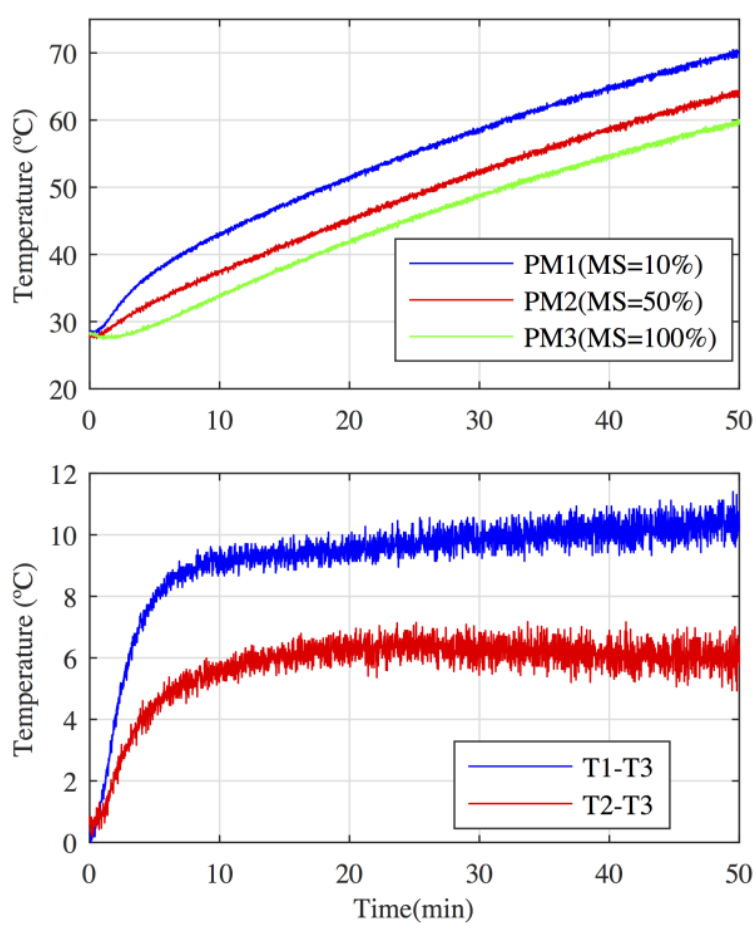

Fig. 15. a) Temperature of PMs 1 to 3 for case \#6 in Table IV; b) temperature difference among demagnetized and fully magnetized magnets. $\mathrm{I}_{\mathrm{q}}=0.5 \mathrm{pu}, \mathrm{I}_{\mathrm{d}}=0.5 \mathrm{pu}, \mathrm{Ihf}_{\mathrm{f}}=0.25 \mathrm{pu}, \mathrm{fh}_{\mathrm{h}}=250 \mathrm{~Hz}$ and $\mathrm{Wr}_{\mathrm{r}}=1000 \mathrm{rpm}$.

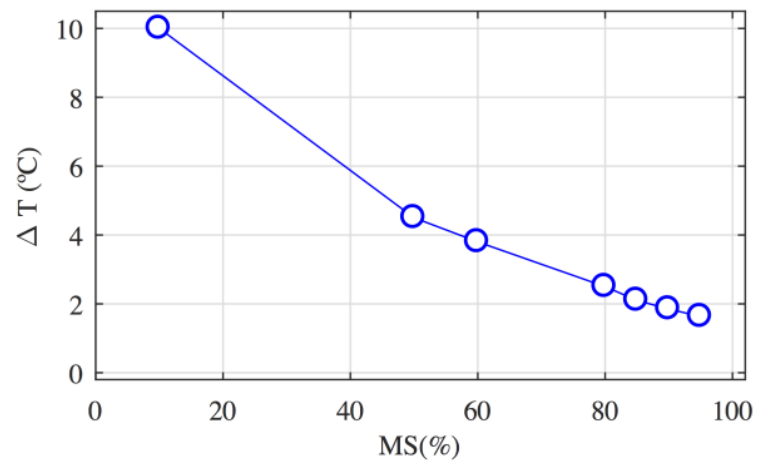

Fig. 16. Temperature difference between a demagnetized and a fully magnetized magnet for all cases in Table IV.

Fig. 16 shows the temperature gradient between demagnetized and fully magnetized magnets for all the cases shown in Table IV. Two facts can be noticed from this figure. First, relative small reductions of the MS with respect to the fully magnetized case produce a noticeable increase of the temperature ( $\approx 1,8$ degrees for $95 \% \mathrm{MS})$. Second, temperature increases almost linearly as the MS decreases. A better understanding of this behavior is a topic of ongoing research.

It is finally noted that it is not straightforward, or even possible, to isolate the PM temperature increase due to MS variation effect and to the injection of flux-weakening current in a PMSM due to several reasons:

- Flux weakening current affects to the harmonic content of the air-gap flux, which will induce additional losses in the PMs. Consequently, results obtained with different levels of the flux weakening current cannot be compared directly, unless the effect of flux harmonics is compensated.
- Flux weakening current will also induce additional losses in the stator windings and stator core, impacting therefore the rotor temperature.

- Flux weakening current will affect to all PM by the same amount, meaning that it is not possible to produce unbalances among magnets.

Finally, a set of FEA simulations have been carried out to analyze PM losses during flux weakening with and without including MR effects; machine parameters being shown in Table III, results for different machine speeds and flux weakening levels being shown in Table V. It can be observed that the efficiency of the machine decreases during FW when the MR effect is considered, due to the increase of PM losses.

TABLE V: MACHINE EFFICIENCY VARIATION

\begin{tabular}{|l|c|c|c|c|c|c|}
\hline Rotor speed & 500 & 1000 & 1200 & 1400 & 1600 & 1800 \\
\hline FW $(\%)$ & 0 & 0 & 55 & 71 & 80 & 86 \\
\hline Efficiency without MR effect. & 0.877 & 0.912 & 0.922 & 0.938 & 0.934 & 0.902 \\
\hline Efficiency with MR effect. & 0.877 & 0.912 & 0.919 & 0.934 & 0.930 & 0.897 \\
\hline
\end{tabular}

Development of methods able to measure the effect of the field weakening current on PM losses in PMSM is a subject of ongoing research.

\section{CONCLUSIONS}

This paper analyzes the influence of magnetoresisitive effect on Eddy current losses in NdFeB PMs commonly used in PMSMs. It has been shown that variations in the PM MS or in the PM flux due to flux weakening current, results in a variation in the PM Eddy current losses due to magnetoresistive effect. This increases PM losses and consequently PM temperature. Experimental results using both magnet samples in a simplified geometry and a PMSM have been provided to confirm the analysis. The paper has focused on conventional PMSM designs. However, the study and conclusions presented in this paper can be especially relevant for VF-PMSM. This type of machines can be magnetized-demagnetized during normal operation; based on the experimental results shown in this paper the increase in the losses when the machine operates with low magnetization levels might need to be considered both for the machine design and for the control strategies as well.

\section{APPENDIX I}

The setup developed for the analysis of Eddy current loses in PM samples is shown in Fig. 1. Core is made of iron powder blocks to minimize Eddy current loses. Shape and dimensions of the central column matches those of PM samples (see Figs. 1b and 1d) and a coil. A flexibly PCB (0.2mm thickness) equipped with field and temperature sensors is attached to the PM (see Fig. 1a and 1c) [23]. The field measurement bandwidth ranges from DC up to 300 $\mathrm{kHz}$. PM temperature is measured using a platinum RTD thermistor [24]. The whole measurement system adds an airgap of $0.8 \mathrm{~mm}$ between the PM and the core central column (see Fig. 1).

The coil consists of 7 paralleled wires, with 335 turns in total. It is fed from a $30 \mathrm{~kW} \mathrm{H}$-Bridge power converter (Fig. 


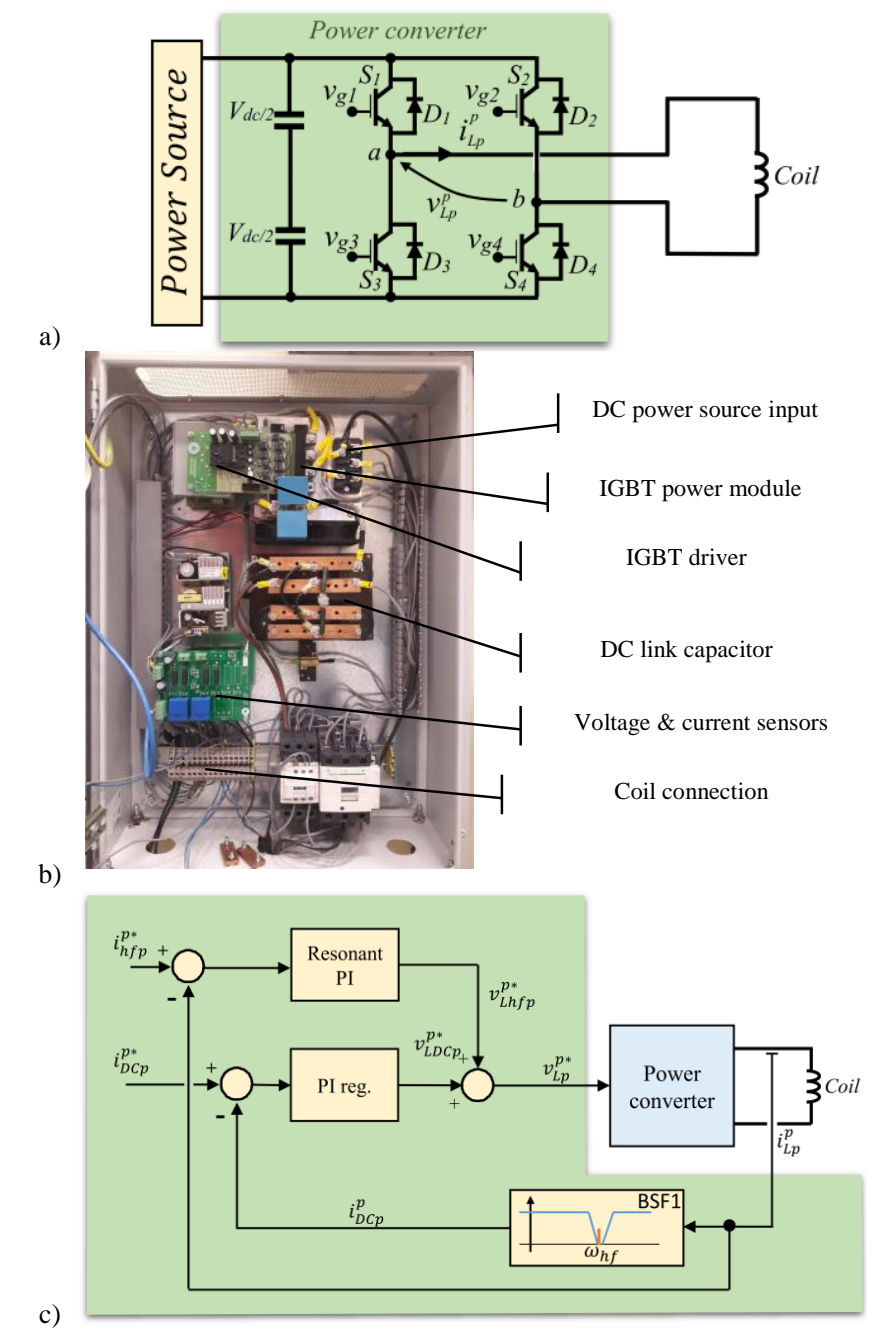

Fig. 17. a) Schematic representation of the power converter, b) picture of the H-bridge powe converter and c) power converter current control block diagram.

17a) shows the power converter control block diagram, Fig. $17 \mathrm{~b}$ shows a picture of the power converter. Fig. 17c shows the control block diagram of the power converter: A DC current, $i_{D C p}^{p^{*}}$, is injected into the coil to weaken or intensify the PM flux. A high frequency (HF) current, $i_{h f p}^{p^{*}}$, is superimposed on top of the DC current, which is used to induce a high frequency flux through the PM (this resembles flux harmonics in PMSMs). A PI controller is used to control $i_{D C p}^{p^{*}}$, while a resonant controller is used to control $i_{h f p}^{p^{*}}$. A band-stop filter $(B S F 1)$ is used prevent the reaction of the PI controller to the injected high frequency signal.

\section{ACKNOWLEDGMENT}

The authors would like to acknowledge BOMATEC for providing magnet samples.

\section{REFERENCES}

[1] Jang-Mok Kim and Seung-Ki Sul, "Speed control of interior permanent magnet synchronous motor drive for the flux weakening operation," in IEEE Transactions on Industry Applications, vol. 33, no. 1, pp. 43-48, Jan/Feb 1997. doi: 10.1109/28.567075
[2] Q. Li, T. Fan, X. Wen and P. Ning, "An Analytical Approach to Magnet Eddy-Current Losses for Interior Permanent-Magnet Synchronous Machines During Flux Weakening," in IEEE Transactions on Magnetics, vol. 51, no. 8, pp. 1-9, Aug. 2015. doi: 10.1109/TMAG.2015.2423267

[3] Z. Q. Zhu, Y. S. Chen and D. Howe, "Iron loss in permanent-magnet brushless AC machines under maximum torque per ampere and flux weakening control," in IEEE Transactions on Magnetics, vol. 38, no. 5, pp. 3285-3287, Sep 2002. doi: 10.1109/TMAG.2002.802296

[4] D. Fernandez, D. Reigosa, M. Martinez, J. M. Guerrero and F. Briz, "Influence of Magnetoresistance and Temperature on Permanent Magnet Condition Estimation Methods Using High Frequency Signal Injection”, 2017 IEEE Energy Conversion Congress and Exposition (ECCE), Cincinnati, OH, 2017, pp. 3201-3207.

[5] Seok-Hee Han, T.M. Jahns and Z.Q. Zhu, "Analysis of rotor core Eddy-Current losses in interior permanent magnet synchronous machines". IEEE Trans. on Ind. Appl., 46(1):196-205, Jan.-Feb. Oct. 2010.

[6] M. R. Shah and S. B. Lee, "Rapid Analytical Optimization of Eddycurrent Shield Thickness for Associated Loss Minimization in Electrical Machines". IEEE Trans. on Ind. Appl., 42(3):642-649, May-June 2006.

[7] H. Toda, Z. Xia, K. Atallah and D. Howe, "Rotor eddy-current loss in permanent magnet brushless machines". IEEE Trans. on Mag., 40(4):2104-2106, Jul. 2004.

[8] J. Pyrhönen, S. Ruoho, J. Nerg, M. Paju, S. Tuominen, H. Kankaanpää, R. Stern, Aldo Boglietti and N. Uzhegov "Hysteresis Losses in Sintered NdFeB Permanent Magnets in Rotating Electrical Machines," in IEEE Transactions on Industrial Electronics, vol. 62, no. 2, pp. 857-865, Feb. 2015.doi: 10.1109/TIE.2014.2354597

[9] K. Yuuki, K. Sakai, and H. Mochikawa, "Variable magnetic flux drive system," U.S. Patent Application 12/678929, Sep. 16, 2008

[10] N. Limsuwan, T. Kato, K. Akatsu and R. D. Lorenz, "Design and Evaluation of a Variable-Flux Flux-Intensifying Interior PermanentMagnet Machine," in IEEE Transactions on Industry Applications, vol. 50, no. 2, pp. 1015-1024, March-April 2014.doi: 10.1109/TIA.2013.2273482

[11] T. Fukushige, N. Limsuwan, T. Kato, K. Akatsu and R. D. Lorenz, "Efficiency Contours and Loss Minimization Over a Driving Cycle of a Variable Flux-Intensifying Machine," in IEEE Transactions on Industry Applications, vol. 51, no. 4, pp. 2984-2989, July-Aug. 2015.doi: 10.1109/TIA.2015.2404918

[12] D. Fernandez, D. D. Reigosa, J. M. Guerrero, Z. Q. Zhu and F. Briz, "Permanent-Magnet Magnetization State Estimation Using HighFrequency Signal Injection," in IEEE Transactions on Industry Applications, vol. 52, no. 4, pp. 2930-2940, July-Aug. 2016. doi: 10.1109/TIA.2016.2541616

[13] D. Díaz Reigosa, D. Fernandez, Z. Q. Zhu and F. Briz, "PMSM Magnetization State Estimation Based on Stator-Reflected PM Resistance Using High-Frequency Signal Injection," in IEEE Transactions on Industry Applications, vol. 51, no. 5, pp. 3800-3810, Sept.-Oct. 2015.doi: 10.1109/TIA.2015.2437975

[14] S. O. Kasap, "Principles of electronic materials and devices," Third Edition 2006, ISBN 0-07-295791-3.

[15] B. Idzikowski, M. Wolf, A. Handstein, K. Nenkov, F. Stobieski and K.-H. Muller, "Inverse giant magnetoresistance in granular $\mathrm{Nd} / \mathrm{sub}$ 2/Fe/sub 14/ B a-Fe," INTERMAG Magnetics Conference, Oct. 1997

[16] S. H. Han, T. M. Jahns and Z. Q. Zhu, "Design Tradeoffs Between Stator Core Loss and Torque Ripple in IPM Machines," in IEEE Transactions on Industry Applications, vol. 46, no. 1, pp. 187-195, Jan.-feb. 2010. doi: 10.1109/TIA.2009.2036664.

[17] K. Yamazaki and Y. Seto, "Iron loss analysis of interior permanentmagnet synchronous motors-variation of main loss factors due to driving condition," in IEEE Transactions on Industry Applications, vol. 42, no. 4, pp. 1045-1052, July-Aug. 2006. doi: 10.1109/TIA.2006.876080.

[18] S. H. Han, W. L. Soong and T. M. Jahns, "An Analytical Design Approach for Reducing Stator Iron Losses in Interior PM Synchronous Machines During Flux-Weakening Operation," 2007 IEEE Industry Applications Annual Meeting, New Orleans, LA, 2007, pp. 103-110. doi: 10.1109/07IAS.2007.36.

[19] D. F. Alonso, D. Reigosa, J. M. Guerrero, C. Suarez and F. Briz, "Impact of machine magnetization state on permanent magnet losses in permanent magnet synchronous machines," 2017 IEEE Energy 
Conversion Congress and Exposition (ECCE), Cincinnati, OH, 2017, pp. 5840-5845. doi: 10.1109/ECCE.2017.8096967

[20] K. Atallah, D. Howe and D. Stone, "Rotor loss in permanent-magnet brushless AC machines". IEEE Trans. on Ind. Appl., 36(6):16121618, Nov.-Dec. 2000.

[21] J. D. McFarland, T. M. Jahns, A. M. EL-Refaie and P. B. Reddy, "Effect of magnet properties on power density and flux-weakening performance of high-speed interior permanent magnet synchronous machines," 2014 IEEE Energy Conversion Congress and Exposition (ECCE), Pittsburgh, PA, 2014, pp. 4218-4225. doi: 10.1109/ECCE.2014.6953975

[22] D. D. Reigosa, D. Fernandez, T. Tanimoto, T. Kato and F. Briz, "Sensitivity Analysis of High-Frequency Signal Injection-Based Temperature Estimation Methods to Machine Assembling Tolerances," in IEEE Transactions on Industry Applications, vol. 52, no. $6, \quad$ pp. 4798-4805, Nov.-Dec. 2016.doi: 10.1109/TIA.2016.2586757.

[23] ChenYang - sensors and measurements, "Selection guide of hall effect sensor elements/ICs," CYSJ106C, Mar. 23, 2017. [Online] Available: http://www.hallsensors.de

[24] Vishay - Sensors, Temperature, Thin Film RTD "Platinum SMD Flat Chip Temperature Sensor," PTS AT, Jun. 2, 2017. [Online]. Available: http://www.vishay.com/sensors/sensorstemperature/platinum

[25] S. Ruoho, J. Kolehmainen, J. Ikaheimo and A. Arkkio, "Interdependence of Demagnetization, Loading, and Temperature Rise in a Permanent-Magnet Synchronous Motor," in IEEE Transactions on Magnetics, vol. 46, no. 3, pp. 949-953, March 2010.

[26] Zverev, A.I.:"Handbook of filter synthesis". Wiley New York, 1967

[27] J. C. Urresty, R. Atashkhooei, J. R. Riba, L. Romeral and S. Royo, "Shaft Trajectory Analysis in a Partially Demagnetized PermanentMagnet Synchronous Motor," in IEEE Transactions on Industrial Electronics, vol. 60, no. 8, pp. 3454-3461, Aug. 2013. doi: 10.1109/TIE.2012.2213565 